\title{
ON THE CLASSIFICATION AND DIAGNOSIS OF PATHOLOGICAL GRIEF
}

\author{
Margaret Stroebe, Maarten van Son, Wolfgang Stroebe, \\ Rolf Kleber, Henk Schut, and Jan van den Bout \\ Research Institute for Psychology and Health, Utrecht University
}

\begin{abstract}
It has been suggested that pathological grief should become either a separate category of mental disorder or be integrated within existing, extended classifications in systems such as the Diagnostic and Statistical Manual of Mental Disorders. Despite strong arguments for inclusion, and advancements by scientists toward development of diagnostic classification, there has been a lack of critical evaluation. Several issues need further scrutiny and clarification. These concern the definition of pathological grief, the distinction of pathological from normal grief, its relationship with other disorders, and the lack of agreement among scientists about criteria for pathological grief. Further research needs to focus on delineation of syndromes that comprise "pathological grief," and on derivation of acceptable, valid, diagnostic criteria. Evaluation of the ramifications — both positive and potentially negative — associated with the revision of the diagnostic status of pathological grief needs also to be undertaken. (C) 2000 Elsevier Science Ltd
\end{abstract}

Near the end of his life Sigmund Freud was consulted by a woman who had become depressed following the death of her husband. After listening to her, Freud quietly stated, "Madam, you do not have a neurosis, you have a misfortune." (Wahl, 1970, p. 137)

I know of only one functional psychiatric disorder whose cause is known, whose features are distinctive, and whose course is usually predictable, and this is grief, the reaction to loss. Yet this condition has been so neglected by psychiatrists that until recently it was not even mentioned in the indexes of most of the best-known general textbooks of psychiatry. (Parkes, 1986, p. 26)

THE EMOTIONAL REACTION to the loss of a loved one, grief, encompasses intense personal anguish for most people, and is associated with increased risk for a variety of psychological and somatic ailments (Middleton, Raphael, Martinek, \& Misso, 1993; Parkes, 1996; Shuchter \& Zisook, 1993; Stroebe \& Stroebe, 1987). In some cases, these

Correspondence should be addressed to Margaret Stroebe, Research Institute For Psychology and Health, Utrecht University, P.O. Box 80140, 3508 TC Utrecht, The Netherlands. 
reactions reach an intensity and/or duration that could, according to criteria adopted in standard classification systems, be labeled "mental disorder" (Schut, de Keijser, van den Bout, \& Dijkhuis, 1991). Foremost among such systems are the Diagnostic and Statistical Manual of Mental Disorders, fourth edition (DSM-IV; American Psychiatric Association, 1994), and the International Classification of Diseases and Related Health Problems (ICD-10; World Health Organization, 1992). Pathological grief has indeed been suggested as a separate diagnostic diagnosis category by bereavement experts for inclusion in the DSM system.

Should "pathological grief" (or "complicated grief," as some contemporary writers prefer) be included as a separate diagnostic category of mental disorder in future editions of such manuals? Given the citations included above, it is easy to see that the answer to this question may not be simple. In fact, changes have recently occurred in diagnostic categorization, between the third and fourth editions of the DSM, reflecting clearer recognition and incorporation of pathological grief within the current system. This would seem compatible with the establishment of pathological grief as a diagnostic category in future editions. It is possible that pathological grief will either become a separate category, or that bereavement will be incorporated, for example, as a stressor within a category of event-related disturbances, including posttraumatic stress disorder (PTSD), in the next edition of DSM (and/or ICD). Since DSM and ICD are accepted as the leading guides for practitioners, inclusion could be expected to have far-reaching impact. ${ }^{1}$

There are reasons to argue in favor of such a development, and, as we shall see below, some experts have made strong cases in support of this. Nonetheless, there has been an absence of discussion in the scientific literature about readiness for, and implications of, establishing a category of pathological grief. A number of key issues need clarification. Critical are those that concern the nature of pathology in the grief domain, for example: How does one define pathological grief? What are valid criteria for a classification of pathology? It is also important to raise questions about the impact of creating a category of mental disorder on the psychological phenomenon of grief itself: What changes in the conception of grief would be likely to follow? What societal implications and health-care consequences would such a development bring about?

Concerns about provision of appropriate care for the bereaved underlie the need to address these unresolved issues. On the one hand, some bereaved people need and benefit from counseling or therapeutic assistance in one form or another-and may

\footnotetext{
${ }^{1}$ In this article, we refer to "diagnostic classification/categorization," adopting similar usage to that employed in DSM-IV and by the researchers that we cite. It is important to note that the $D S M$ classification system was not designed to be used as a diagnostic instrument in and of itself-nor, when we refer to "diagnosis," do we assume that this is the case. We assume that the $D S M$ system is to be used as a guideline, offering criteria, for making diagnoses by clinicians and researchers, the proper use of which requires specialized clinical training. Its stated purpose is to provide ". . . clear descriptions of diagnostic categories in order to enable clinicians and investigators to diagnose, communicate about, study, and treat people with various mental disorders" (American Psychiatric Association, 1994, p. xxvii). Likewise, the issues discussed in this article are done so with the aim of working toward accurate representation of complicated forms of grief, and not to enable the labeling of pathological grief through the use of a diagnostic instrument.
} 
not have access to this if there is no diagnostic category for pathological grief. On the other hand, it is important to develop valid guidelines for whether and when bereaved people need such help and to ensure that provision of therapy is appropriate.

Given that many experts are currently arguing in favor of including pathological grief in formal categorizations of mental disorders, it would seem timely to pause and consider a number of critical issues relating to such a revision. The primary purpose of this article is to open discussion on key points, and to identify unresolved issues that bear on the possible addition of pathological (or complicated) grief to diagnostic manuals.

\section{PATHOLOGICAL GRIEF AS A POSSIBLE CATEGORY OF MENTAL DISORDER}

\section{The Current Position}

DSM classification. In considering the issue of inclusion of pathological grief into a classification system of mental disorders, our discussion focuses on DSM and not ICD. However, there is considerable overlap between the two classification systems (cf. DSM-IV; American Psychiatric Association, 1994, pp. xx-xxi; Kendell, 1991), such that the concerns raised here have relevance also for development and application of the ICD system.

$D S M-I V$ defines a mental disorder as "a clinically significant behavioral or psychological syndrome or pattern that occurs in an individual and that is associated with present distress (e.g., a painful symptom) or disability (i.e., impairment in one or more important areas of functioning) or with a significantly increased risk of suffering death, pain, disability, or an important loss of freedom. In addition, this syndrome or pattern must not be merely an expectable and culturally sanctioned response to a particular event, for example, the death of a loved one" (American Psychiatric Association, 1994, p. xxi). A general criterion for disorders, namely, that the condition causes suffering and/or obstructs normal professional/social functioning, also applies. Along these lines, to distinguish pathological from normal grief, one would seek to establish an increased risk of suffering from the itemized debilities, on the understanding that these are not merely to be expected or sanctioned, given the bereavement. One cannot expect to establish a cut-and-dried dividing line between normal and pathological grief; clinical evaluation is also integral.

What is the current position of pathological grief within the existing diagnostic category system of DSM? Scrutiny of the last two editions of the manual, DSM-III-R (American Psychiatric Association, 1987) and DSM-IV (American Psychiatric Association, 1994), shows greater recognition in the latter edition that bereavement may be associated with complicated reactions. For example, in the latter edition, simple bereavement is no longer excluded as a relevant feature in the classification of PTSD. In DSM-III-R and DSM-IV, uncomplicated bereavement is excluded from diagnostic features, both in the categories Major Depressive Episode (under the diagnostic class of Mood Disorders) and Posttraumatic Stress Disorder (under Anxiety Disorders). It features under V code classifications. V Codes encompass classes of conditions that "may be a focus of clinical attention" (DSM-IV, American Psychiatric Association, 1994, p. 9), but are not counted within the major diagnostic classes, and are thus not considered to be manifestations of a mental disorder.

$D S M-I V$ clarifies the boundary between Major Depressive Episode and Bereavement in the following way: "After the loss of a loved one, even if depressive symptoms are of 
sufficient duration and number to meet criteria for a Major Depressive Episode, they should be attributed to bereavement rather than to Major Depressive Episode, unless they persist for more than two months or include marked functional impairment, morbid preoccupation with worthlessness, suicidal ideation, psychotic symptoms, or psychomotor retardation" (American Psychiatric Association, 1994, p. 326; cf. also, Appendix D, p. 780). The complex syntax of this statement makes it difficult to comprehend. It has been interpreted as stating that grief persistent beyond a duration of only 2 months following a bereavement merits inclusion within the diagnostic category of Major Depressive Disorder (which is characterized by one or more Major Depressive Episodes). It seems unlikely that any experienced task force behind the formulation in DSM- $I V$ would hold the view that intense grieving ceases after 2 months. It is well-accepted in the scientific literature that intense grief for most people persists far beyond this period (Parkes, 1986; Shuchter \& Zisook, 1993). Rather, the intention behind the DSM formulation may be to indicate the possibility that symptoms reaching the level of a full-blown major depressive episode after 2 months may need clinical intervention. As Prigerson, Frank, et al. (1995) commented, "The DSM-IV criteria have partially addressed the possible need for treatment early in the course of bereavement by specifying that the diagnosis of major depressive disorder may be given as early as 2 months after the loss of a loved one" (p. 22). Following this line of reasoning, within the first 2 months, such symptomatology may be reflective of intense grieving and not Major Depressive Episode.

In DSM-IV, rather than excluding simple bereavements from the PTSD category, as in $D S M-I I I-R$, causes behind the development of problematic symptomatology are described as " . . learning about unexpected or violent death . . or threat of death ... experienced by a family member or close associate" (American Psychiatric Association, 1994, p. 424). Again, then, in the more recent revision, certain types of bereavement do qualify as prerequisite for the development of PTSD, although it must be noted that this makes the scope extremely broad: any unexpected death could lead to PTSD.

Bereavement is also considered under the Adjustment Disorders classification, the diagnosis being made instead of Adjustment Disorder ". . . when the reaction is an expectable response to the death of a loved one" (American Psychiatric Association, 1994, p. 626). It is considered an Adjustment Disorder ". . . when the reaction is in excess of, or more prolonged than, what would be expected" (American Psychiatric Association, 1994, p. 626).

Finally, bereavement is a DSM-IV V-Code or condition that may be a focus for clinical attention, defined for use when ". . . the focus of clinical attention is a reaction to the death of a loved one. As part of their reaction to the loss, some grieving individuals present with symptoms characteristic of a Major Depressive Episode. . . The diagnosis of Major Depressive Disorder is generally not given unless the symptoms are still present 2 months after the loss. However, the presence of certain symptoms that are not characteristic of a "normal" grief reaction may be helpful in differentiating bereavement from a Major Depressive Episode" (American Psychiatric Association, 1994, p. 684). This statement, again, is difficult to understand: It seems to mean that bereavement would be of potential clinical attention if, after 2 months, symptoms atypical of normal grief are evident-and which are distinguishable, too, from Major Depressive Episodes, but these are not specified.

It is remarkable that the condition bereavement merits attention in such a range of different disorder categories as those described above. This reflects the complexity 
and possible multidimensionality of the phenomenon, an issue for consideration in future $D S M$ development. It is also noteworthy that reactions to loss experiences have in the past been an exclusion from the definition of mental disorders in the DSM system, this having begun to change with the introduction of PTSD (a development that is somewhat inconsistent with the text cited above, from American Psychiatric Association, 1994, p. xxi). The system itself would change in nature further still (i.e., the potential range of categories to be considered for inclusion would be extended) were pathological grief to be included.

Contemporary viewpoints. Although differences between DSM-III-R and DSM-IV could be interpreted as reflecting a gradual integration of bereavement within the existing diagnostic categorization system, this does not necessarily mean that further amendments to create a new category or subtype of disorder will be forthcoming in future editions. Perhaps the changes are viewed as sufficient to ensure that forms of complicated bereavement receive diagnosis when appropriate. That this is not, in fact, a generally accepted viewpoint can be concluded from the statements made by prominent writers in the field of bereavement (e.g., Hartz, 1986; Horowitz, Bonanno, \& Holen, 1993, Horowitz et al., 1997; Jacobs, 1993; Rando, 1993; Raphael, 1989), all of whom argue in favor of diagnostic status for pathological grief. Detailed consideration has been provided by two of these leading experts, namely, Jacobs and Horowitz (and his colleagues). Both Horowitz et al. (1993, 1997) and Jacobs (1993) have argued that pathological grief could have separate categorization, each suggesting diagnostic features and lists of criteria for inclusion in future editions of DSM. These two formulations are, however, somewhat different.

Horowitz et al. (1993) argued that, "Pathological grief deserves a place in the diagnostic nomenclature," either separately, or under PTSD, in the following way:

... the establishment of a pathological grief disorder diagnosis or modification of the PTSD stressor criteria to include bereavement as a stressor that can incite a disorder in predisposed persons. (p. 260)

Jacobs (1993), noting that the DSM-IV authors are considering the introduction of a new category of disorders called stress-related disorders, went so far as to argue that:

This category of disorders would include the etiological implication that an environmental stressor causes the disorders. This assumption is justified as much for pathologic grief as for traumatic disorders, and therefore pathologic grief ought to be included as a category of acute stress disorder. (pp. 356-357)

Although agreed on the eventual integration of pathological grief in the DSM system, these authors differ in their conceptions as to how this should take place. In line with their psychodynamic stress theory perspective (see Horowitz, 1986), Horowitz and his colleagues (Horowitz, Wilner, Marmar, \& Krupnick, 1980; Horowitz et al., 1993, 1997) see grief as incorporating intense posttraumatic stress reactions (e.g., reactions of denial and re-experiencing). These authors argue for a single set of criteria for pathological grief (for the criteria, see Horowitz et al., 1993, p. 270) or, more recently, for complicated grief disorder (for the criteria, see Horowitz et al., 1997, p. 909), leading to a single diagnostic category and encompassing varieties of response that are personality-based. 
In contrast to Horowitz's position, Jacobs (1993) argued for subtypologies of pathological grief (for the criteria, see Jacobs, 1993, pp. 363-369). Following the attachment theory perspective (cf. Bowlby, 1980; Parkes \& Weiss, 1983), he argued that pathological variants of grief would be defined in terms of the absence or extreme intensification of separation anxiety. In Jacobs' view

. . . the syndromes of pathologic grief, with one exception [absent grief], do not differ qualitatively from those of normal grief. [They are]. . . dysfunctional departures from a tolerable intensity of separation distress or deviations in the duration of such distress. . syndromes of pathologic grief are functional disorders in which normal attachment behavior and physiology, which are evoked by a loss, become aberrant. (Jacobs, 1993, p. 13).

Conclusions. Although DSM-IV description provides a more precise differentiation between grief reactions and other related disorders than DSM-III-R, the criteria for distinction/overlap remain unclear. Some leading scientists have argued strongly in favor of the establishment of pathological grief as a separate diagnostic category, even to the extent of already developing diagnostic criteria. However, those in favor of changing the status have derived different diagnostic criteria for pathological grief, reflecting different definitions and understanding of the construct. The potential location(s) of pathological/complicated grief in the system have also been insufficiently discussed. For example, we have seen above that it could potentially be placed among depressive disorders and/or anxiety disorders, but there has been lack of discussion in the literature about the respective claims to status. In our view, there is a need for critical appraisal of such key issues underlying the creation of a category of pathological grief in diagnostic systems, and consideration of the justification and implications of inclusion.

\section{PATHOLOGICAL GRIEF AS A CATEGORY OF MENTAL DISORDER: UNRESOLVED ISSUES}

Four aspects relating to the status of pathological grief as a mental disorder are discussed below: namely, those concerning the definition of pathological grief; the diversity in conceptualizations; problems in distinguishing normal from pathological grief; and the complex relationship with related disorders (these are not mutually exclusive discussion points). It needs to be acknowledged that similar problems of classification may pertain to other diagnostic categories already in the mental disorders classification system (cf. Kleber, Figley, \& Gersons, 1995, for the case of posttraumatic stress reactions). In fact, there is a substantial, sophisticated literature examining the boundaries between pathology and normality, debating the strengths and weaknesses of alternative definitions of disorder (e.g., Lilienfeld \& Marino, 1995; Wakefield, 1992), and contesting the rationale, alternatives and standards of the DSM classification system (e.g., Barlow, 1991; Follette, 1996). Nevertheless, there are reasons to focus on pathological grief. The fact that discussion has not been resolved for other disorders with classification status indicates general shortcomings in such systems (due, among other things, to the complexity of the phenomena in question). This is no reason to ignore complications in our specific case, and it should serve to alert one to the likelihood that such problems pertain for already existing categories. Discussion would seem particularly fruitful at a pre-inclusion time point: as McFarlane (1995) pointed out for the case of PTSD, "The authority that the DSM-III has come to acquire means 
that the conclusions of any revision are perhaps not scrutinized as thoroughly as necessary for the health of the traumatic stress discipline" (p. 34).

\section{Lack of Consensus in Defining Pathological Grief}

If there is lack of clarity about the nature of the diagnostic disorder to be included in a classification system, this must have implications for creation of such a category in the first place. In fact, problems in the definition of "pathological grief" are well-recognized by bereavement researchers. According to Middleton et al. (1993):

The field is still struggling to validate and operationalize the construct of "normal" grief. ... When the focus is extended to include a range of "abnormal" forms of grief, the difficulties are compounded. (p. 44)

There is great diversity in terms denoting variation from normal grief, with use of such labels as: absent (Deutsch, 1937), abnormal (Pasnau, Fawney, \& Fawney, 1987), complicated (Sanders, 1989), distorted (Brown \& Stoudemire, 1983), morbid (Sireling, Cohen, \& Marks, 1988), maladaptive (Reeves \& Boersma, 1990), atypical (Jacobs \& Douglas, 1979), intensified and prolonged (Lieberman \& Jacobs, 1987), unresolved (Zisook \& DeVaul, 1985), neurotic (Wahl, 1970), dysfunctional (Rynearson, 1987), and the frequently used division into chronic/delayed/inhibited grief (cf. Lindemann, 1944; Parkes \& Weiss, 1983; Raphael, Middleton, Martinek, \& Misso, 1993). While differences in labeling, per se, do not necessitate a difference in conceptualization, examination of the above terms is sufficient to indicate at least a variety of connotations.

Just as there are many different taxonomies and labels, so is there a lack of consensus with respect to the definition of, and/or diagnostic criteria for pathological grief (cf. Jacobs \& Kim, 1990; Middleton, Burnett, Raphael, \& Martinek, 1996). To illustrate, according to Middleton et al. (1993), pathological bereavement hallmarks are the ". . intensification or inhibition of the phenomena of normal bereavement" ( $p$. 51). They define pathological grief in the following way:

Where grief for a particular individual, in a particular culture, appears to deviate from the expected course in such a way that it is associated with excessive or prolonged psychological or physical morbidity, it may be labelled as pathological. (p. 44)

It is important to note the identification of physical morbidity by these authors. Bereavement is associated with detrimental physical health consequences (Stroebe \& Stroebe, 1987), and yet, typically, these feature neither in definitions of pathological grief, nor in the DSM system.

Different from the above is the formulation of Zisook, DeVaul, and Click (1982), Zisook and Lyons (1990), and Shuchter and Zisook (1993), who define complicated grief reactions in terms of the process of resolution of grief (unresolved grief), thereby referring to either absent, delayed, intensified, or prolonged aspects of uncomplicated bereavement. Although they argue that the concept has clinical validity, they acknowledge that it is overly simplistic, since total resolution is rarely found (Shuchter \& Zisook, 1993).

It is apparent that some common elements run through these definitions, while, at the same time, different criteria are suggested, and neither of them addresses the is- 
sue how to distinguish normal from pathological grief very specifically. In addition, the problem in defining what is meant by norm, and by normal remains. Cross-cultural differences in understanding what is normal versus abnormal grief demonstrates how difficult these distinctions are to make, and how hard it is to make generalizations (cf. Stroebe \& Stroebe, 1987).

\section{Different Theoretical Conceptualizations of Pathological Grief}

Not only are there differences in labeling and definition, as illustrated above, but conceptualizations of pathological grief differ according to the theoretical approach and interest of the particular investigators. While the DSM system is formally atheoretical in nature, it nevertheless seems difficult to conceptualize pathological grief without reference to theoretical underpinnings. Again, although such an argument can be raised for other disorders, this neither minimizes the relevance of the argument nor the need to examine the relationship between theoretical and classification systems here. Furthermore, contemporary perspectives need further reconciliation before being assimilated within a single diagnostic framework.

Conceptualization in terms of extreme stress. In their analysis of pathological grief, Horowitz et al. (1993) basically follow a stress approach, although Horowitz's psychodynamic orientation should also be acknowledged. Stress theory (cf. Lazarus \& Folkman, 1984) views bereavement as a stressful life event that may overtax the coping resources of the individual (particularly one who is predisposed) and put him or her at risk of disorder. As noted above, Horowitz et al. $(1993,1997)$ based their definition of pathological grief on a single set of criteria, following their personality-based explanation of symptom formation and argue for a single diagnostic category in DSM, suggesting diagnostic criteria along unitary lines. According to Horowitz et al. (1993), this approach could place bereavement as a stressor within a modified set of PTSD criteria, one that can incite a disorder in predisposed individuals. In their more recent article, Horowitz and his colleagues (Horowitz et al., 1997) have argued the need for a separate diagnostic category of complicated grief disorder. This is discussed below, in the context of phenomenological analyses of pathological grief.

There are both theoretical and empirical arguments in favor of Horowitz's approach in terms of PTSD (cf. Brom, Kleber, \& van den Bout, 1993). Nevertheless, it must be realized that there are also differences in symptom patterns between pathological grief and PTSD (for further debate, see Brom et al., 1993, compared with Stroebe, Schut, \& Stroebe, 1998), causing Brom et al. (1993) to suggest that pathological grief and PTSD should be placed together in a class of event/loss-related disturbances. This would make use of a single, inclusive categorization system potentially less problematic. For example, there would be less likelihood that patterns of reactions to grief that are not traumatic stress symptoms would be overlooked in diagnosis.

Caution is needed for a different reason. Although grief may accentuate pre-existing pathology (cf. Alarcon, 1984; Middleton et al., 1993), there is a lack of empirical evidence to support the assumption that pathological grief is personality-based, that there are predisposed persons, or to explain how such factors impact on the etiology of pathological grief.

Conceptualization in terms of depression. Different but also highly influential in research on pathological grief has been Clayton's depression model of grief, which fo- 
cuses on the emotional reaction of depression following a specific life event, namely bereavement, in conceptualizing the complications of grief (e.g., Clayton, Halikas, \& Maurice, 1972; Clayton, 1990). Clayton based her conceptualization on the study of bereaved persons in a community sample, to determine what proportion met criteria for clinical depression ( $42 \%$ did so at 1 month; $16 \%$ at 1 year). Differences in symptom patterns were identified between grief, on the one hand, and clinical depression symptoms, on the other hand. The latter were said to occur rarely in bereavement, but frequently in severe depression (e.g., retardation, hopelessness, worthlessness, loss of interest in friends). In her more recent article, Clayton (1990) noted that a bereaved person may experience all the symptoms typical for depressed patients (except retardation). The difference, in her view, is that the bereaved person expects to have such symptoms, and has fewer of the symptoms, while the depressed patient also reports feeling changed. Clayton defined pathological grief Clayton defined as a "continued depressive symptom," and treatment "should be that which is given to any depressed patient" (1990, p. 34). Thus, the view of grief that is suggested in Clayton's model (Clayton, 1990; Clayton et al., 1972) is one of a depressive reaction to a life event: following this, extreme depressive symptomatology would be seen as the fundamental manifestation indicating pathology.

Following this approach, then, it would seem reasonable to assume that pathological grief would fall within the framework of depressive disorders (for a critical appraisal, see Karam, 1994). Yet, as other researchers have pointed out, complicated grief is distinct from depressive disorders. Perhaps most indicatively, studies have demonstrated that the former fails to respond effectively to antidepressant treatment (Jacobs, Nelson, \& Zisook, 1987; Pasternak et al., 1991; Prigerson, Frank, et al., 1995). Similar problems to those identified above, with respect to incorporation within PTSD criteria, would apply in this case too: Patterns of reactions unique to complicated grief might be overlooked (cf. Brom et al., 1993; Stroebe et al., 1998). Distinct symptomatology for complicated grief compared with bereavement-related depression or anxiety was indicated by Prigerson, Bierhals, et al. (1996), giving weight to this argument. In statistical analyses, they identified yearning, hallucinations involving the deceased, and preoccupation of thoughts of the deceased, as loading high on the factor "complicated grief," but very poorly on the other two factors, "anxiety" and "depression" (these three factors accounting for $90 \%$ of the variance in the data). Prigerson, Bierhals, et al. (1996) interpret these results as suggesting that symptoms of complicated grief form a distinct clinical entity.

Conceptualization in terms of typologies. Different again from either of these "unitary" approaches are those that consider pathological grief to be evidenced via a variety of different manifestations (e.g., Middleton et al., 1993). This approach is in line with "typology subschools" (e.g., Bowlby, 1980; Lindemann, 1944; Parkes \& Weiss, 1983). This is an equally strong tradition: It grew out of early research that described pathological grief in terms of psychodynamic mechanisms (repressed yearning, self-reproach, denial, etc.) and that was associated with multiple clinical syndromes, including depression (Bowlby, 1963). Later, Bowlby (1980) related pathological patterns (chronic, absent grief, etc.) to cognitive biases about attachment figures. Parkes and Weiss (1983) offered a somewhat different formulation based on observational studies, but similar pathological variants: unanticipated (denial of loss), conflicted, following an ambivalent relationship (delayed or absent grief), and chronic grief, following a dependent relationship where there has been antecedent insecurity. Middleton et al. (1993) likewise 
identified subtypologies of pathological grief. They considered delayed, absent, chronic, unresolved, and inhibited grief, though noting problems with such classification. Such approaches would require multiple classification in DSM, involving the development of a new categorization system of different types of pathological grief, along the lines suggested by Jacobs (1993). Jacobs' (1993) system of differential criteria, which he adapted from Raphael (1989), was based on Lindemann's (1944) original formulation. Despite their wide acceptance in the scientific and clinical literatures, there is poor empirical foundation to support the subtypologies of pathological grief (chronic, inhibited, delayed, etc.). Using cluster analysis, Middleton et al. (1996) recently found no cases of absent or delayed grief (these would seem difficult to ascertain), and chronic grief as a distinct syndrome among a minority $(9 \%)$ of bereaved persons in a community-based study. It is also noteworthy that few specific empirical studies have been conducted among those diagnosed with problems following bereavement, evidence for subtypologies having been derived from community samples (e.g., Parkes \& Weiss, 1983).

At this point in time, the syndromes that have been referred to in the literature have not been adequately investigated and confirmed empirically.

Conceptualization in terms of distinct phenomenology. Prigerson and her colleagues recently conducted longitudinal empirical research to distinguish syndromes of complicated grief, focusing on the differentiation between complicated grief, bereavementrelated depression, and anxiety, for which they identified distinct factors (Prigerson, Frank, et al., 1995; Prigerson, Maciejewski, et al., 1995; Prigerson, Shear, et al., 1996). Symptoms of anxiety appeared to be distinct from depression or grief, the three factors differentially predicting subsequent symptomatology. They argued that complicated grief, defined in terms of empirically derived criteria, is a unique disorder deserving specialized treatment. Prigerson, Bierhals, et al. (1996) replicated their initial findings, extending the sample size and duration of bereavement. In a community sample of 150 mid- to late-life widows and widowers using data that included a 25month follow-up assessment, they again found evidence of complicated grief as a symptom profile distinct from symptoms of bereavement-related depression and anxiety. Salient symptoms, associated with enduring functional impairments, included preoccupation with thoughts of the deceased, disbelief, feeling stunned, and lack of acceptance of the death. The symptoms loading high on the complicated grief factor, but low on the depression and anxiety factors, discussed above, all had to do with the continued relationship with the deceased, suggesting that this disorder may have to do with a disturbance of attachment.

There is overlap, it would seem, between Prigerson, Bierhals, et al.'s (1996) formulation and the chronic grief syndrome, described in classic contributions (e.g., Bowlby, 1980; Lindemann, 1944; Parkes \& Weiss, 1983) and also identified in the community study by Middleton et al. (1996), referred to above. The work of Prigerson and her colleagues has advanced the field by providing better empirical foundation than was the case for the earlier formulations.

Horowitz et al. (1997) likewise argued the case for DSM-IV criteria for complicated grief to be distinct from those for major depressive disorder. In a longitudinal study assessing 70 bereaved spouses (who had answered a newspaper advertisement) at 6 and 14 months, they extracted seven symptoms that they claimed could "serve as potential diagnostic criteria for complicated grief disorder" (p. 909). These were intense intrusive and avoidant thoughts, and maladaptive levels of loss of interest in personal 
activities, thus different from the type of symptomatology identified by Prigerson, Bierhals, et al. (1996), and suggesting, instead, disturbances congruent with the intrusion-avoidance processes that Horowitz has described for PTSD (e.g., Horowitz, 1986). It is also noteworthy that as many as $41 \%$ of this community sample met the diagnostic criteria suggested by Horowitz et al. (1997) for complicated grief disorder 14 months after their bereavement (Jacobs, 1993, noted that approximately $20 \%$ of the bereaved population experienced some form of complicated grief). Horowitz et al. (1997) derived their sample from younger persons who volunteered, because they "wanted to increase the likelihood of psychopathological symptoms" (p. 905), and cautioned that extrapolation could not be made to the prevalence of complicated grief in a bereaved population. Nevertheless, this apparently high proportion raises the question of how strict the criteria for diagnosis are or need to be, causes doubt about how to interpret the results, and suggests the need for further investigation.

Conclusions. The approaches described above represent notable developments in the conceptualization of complicated grief and in establishing its precise relationship to, and degree of, independence from other syndromes. There is growing evidence that complicated grief represents a distinct clinical entity, but further exploration of signs and symptoms that would comprise diagnostic criteria would seem necessary. There is lack of concordance between investigations, reflecting differences in the orientations of the researchers and in the categories of symptoms that they included in their empirical studies. The extent to which there may be conceptual overlap in the derived categories of symptomatology, but differences in use of labels between different investigators needs further consideration. Finally, there has been little consideration of the role of the cultural and societal context in relationship to the phenomenology of pathological and normal grief, despite growing awareness of the need to take cultural variables into account in diagnostic categorization (cf. Kleber et al., 1995; Mezzich, Kleinman, Fabrega, \& Parron, 1996).

\section{The Obscurity of Criteria for "Normal" Versus "Pathological" Grief}

It has so far proved difficult to derive criteria to differentiate normal from pathological grief. Differences in strategies for doing so are evident, and these are still debated and questionable. At what level or intensity or type of symptomatology, or by what other criteria, can "pathological" grief be said to occur, rather than categorizing a reaction to the loss of a loved one as "normal grief" (see Lilienfeld \& Marino, 1995, for appraisal of such distinctions in general)? Should grief be considered pathological when (and because) levels of symptomatology reach an equivalence with criteria for other clinical diagnoses (e.g., depression; PTSD)? Or is it rather the case that meeting the diagnostic criteria for these related disorders should be interpreted differently for bereaved and nonbereaved persons (perhaps taking the time since bereavement as an additional criterion)? Such questions apply also to other disturbances. For instance, the cut-off point between normal reactions to extreme stress and PTSD is also problematic, and assessment somewhat arbitrary (Kleber \& Brom, 1992).

Examination of the literature indicates that a variety of different criteria have been adopted to differentiate normal from pathological grief-until recently with little supportive empirical evidence, and without reference to the theoretical literature on boundaries in psychiatric classification and diagnosis (see e.g., Barlow, 1991; Lilienfeld \& Marino, 1995; Wakefield, 1992). To give a general idea of the range, these are 
listed next. Note that this list is not exhaustive, that the categories are not mutually exclusive, and that researchers sometimes combine them, or different clusters of them.

Statistical approaches. Pathology may be assumed on the basis of statistical techniques defining deviation from the norm. If there is a normal distribution of phenomena, a definition of pathology can be made on the grounds of placement perhaps 1.5 to 2 standard deviations from the norm. An evaluation of problems in viewing disorders as statistical deviance has been provided by, among others, Wakefield (1992), who argued the case that functional abnormality and statistical abnormality do not necessarily go hand in hand. This criticism seems applicable to pathological grief (cf. arguments concerning the difference between statistical and clinical significance). The risk of misdiagnosis (assuming that there is pathology where there is none, and vice versa) would seem high, and application more appropriate for certain research purposes (e.g., to identify factors that distinguish extreme groups from the norm) than for clinical diagnosis. In focusing on the statistical, there is the risk of neglecting the conceptual (e.g., it may exclude the subjective feeling of maladjustment), although, of course, there is no reason why the two aspects cannot be considered together.

Along different lines, statistical procedures have recently been employed to identify core symptomatology of complicated grief, and to address the question whether pathological grief differs qualitatively and/or quantitatively from normality. This promises to be a fruitful channel for further investigation. These methods include cluster and factor analysis, latent class model analyses and signal detection procedures (cf. Horowitz et al., 1997; Middleton et al., 1996; Prigerson, Bierhals, et al., 1996). ${ }^{2}$

Duration. Pathological grief has been assessed according to too excessive or too little duration. Those accepting the so-called phasal approaches to grief, following the descriptions of Bowlby (1980), would be likely to adopt this criterion (cf. Wambach, 1986), since such approaches identify gradual recovery over the course of time. Yet, assessing the implications of different durations of grief is difficult: "Too short" may have many underlying causes reflective of "normality" (the deceased may not actually be grieved over) rather than pathology (there may be inhibited, delayed or absent grief). There is also the possibility of cultural factors in determining when and for how long grieving will occur (Stroebe \& Stroebe, 1987). Finally, different interpretations have been made about the presence/absence of symptomatology across time. For example, some argue that persistent emotional involvement with the deceased often represents healthy adaptation (cf. Shuchter \& Zisook, 1993), while other investigators seem to suggest the opposite (Prigerson, Bierhals, et al. 1996).

Although the time course of grieving is characterized by peaks and troughs, not gradual, consistent diminishing of symptoms, making it sometimes a difficult criterion to use in diagnosis, it should be recognized that headway has been made in bereavement research in the understanding of patterns of grief across time (cf. Middleton et al., 1996). Thus, for example, there is fair consensus about grief that has gone on "too long."

\footnotetext{
${ }^{2} \mathrm{~A}$ further unfamiliar but potentially useful technique for the diagnosis of pathological grief could be the taxometric approach of Meehl (1995), who described mathematical procedures that can be used to classify psychiatric patients (for a critical evaluation, see Garb, 1996). It is beyond the scope of this article to discuss its application here.
} 
Intensity. High scores on grief symptom inventories (e.g., Prigerson, Maciejewski, et al., 1995; Sanders, Mauger, \& Strong, 1985/1991) may be taken as an indicator that grief is running a complicated course. Although high intensity of grief early in bereavement is a good predictor of complications later on, problems in using this criterion remain. For example, there may be avoidance of grief or it may be delayed or inhibited: apparent lack of intensity may mask complications. Or, the complication may lie in the intensity of a specific symptom (e.g., guilt or anger), such that the total score on a checklist may fail to reflect a problem. Furthermore, it needs to be remembered that, even though a high intensity of grief may appear appropriate or normal given the nature of the particular loss, this does not mean that there is no complication in the grieving process, nor any need for intervention.

Also to be taken into account is whether the level of intensity of symptomatology that the person experiences is intolerable or extremely hard to bear (cf. Jacobs, 1993). This would conform with the nonspecific criteria in DSM-IV (e.g., that the condition not only results in suffering, but also in debilitating effects in social, personal, or professional life). It would also fit the concept of mental disorder as formulated in terms of "harm" and social value (Wakefield, 1992), since it would take into account the undesirability of the condition that the person finds him or herself in. Again, however, such an evaluation is hard to make: It seems inappropriate to apply "tolerable" or "not hard to bear" to such losses as that of a child.

Grief processes. Pathology has been assumed in cases where processes such as working through grief or achieving a "resolution" are not to be found, such criteria being central to psychoanalytic and attachment perspectives on recovery from grief (see Stroebe, 1992, for a review). If certain cognitive "tasks" are not undertaken and dealt with, pathology might ensue (cf. Worden, 1991). Adopting such criteria would assume that working through grief is mandatory to recovery. Recent empirical studies have suggested that the processes underlying adaptation may be more complex (Bonanno, Keltner, Holen, \& Horowitz, 1995; Stroebe \& Stroebe, 1991; Wortman \& Silver, 1989).

Differential symptomatology. Middleton et al. (1993) discussed the potential criterion that "Pathological grief might also relate to the presence of different phenomena that would then be seen as pathognomic of this, as opposed to normal grief" (p. 50). An example would be the appearance of somatic symptomatology similar to and reflecting identification with symptomatology apparent during the terminal illness of the deceased person. This criterion, they argued, has not proved helpful in defining criteria for pathological grief. Nevertheless, it is frequently the case that complications of grief manifest themselves with regard to limited, specific aspects (e.g., unabating regret at the omission of some care function during terminal illness), while others remain at a nonproblematic level or duration. The bereaved appears to be "locked" or "stuck" in some aspect of grieving. While these features have been found useful by clinicians, there is little empirical evidence with respect to such "process" variables, or, specifically, with respect to the centrality of obstruction of process in the development of grief pathology. Further conceptual and empirical research is, however, needed.

The work by Prigerson and colleagues, cited above, indicates the potential of a differential symptomatology approach to identify a so-called complicated grief syndrome (e.g., Prigerson, Frank, et al., 1995; Prigerson, Bierhals, et al., 1996). However, additional strategies could nevertheless identify other patterns of symptom presentation following a bereavement. Horowitz et al. (1997) suggested the need for multiaxial di- 
agnoses, “. . . adding axis II personality disorder categories to make distinctions between subgroups, under a single axis I symptom diagnosis of complicated grief disorder or major depressive disorder" (p. 909). This suggestion was made to accommodate possible subtypes of symptomatic presentation after prolonged and unresolved grieving, within the complicated grief disorder category. This novel idea needs further examination.

Disruption of function. Pathology is sometimes stated in terms of major or prolonged functional impairment. This is in line with the nonspecific criterion underlying all categories in DSM-IV, which states that significant suffering and/or functional impairment must be present for diagnostic criteria to be met.

It would also be congruent with the formulation by Wakefield (1992), who argued for a conceptualization of mental disorder in terms of harmful dysfunction, wherein harmful is a value term based on social norms, and dysfunction is a scientific term referring to the "failure of a mental mechanism to perform a natural function for which it was designed by evolution" (p. 373). Problematic, in the context of pathological grief, would seem to be failure to consider that dysfunction may, in fact, represent an adaptive reaction to loss (cf. Lilienfeld \& Marino, 1995). For example, the social network may rally around to support the bereaved while he/she is unable to function effectively, reorganization of the group that misses the deceased may occur, and resources may be made available to help people to cope with the new situation.

Clinical diagnostic assessment for some related disorder. This approach holds that grief should be considered pathological when (and because) levels of symptomatology reach an equivalence with criteria for other clinical diagnoses (e.g,. depression; PTSD). This underlies the reasoning of those who argue for the extension of current diagnostic categories to include pathological grief, rather than for the creation of a new category. Such a viewpoint needs separate consideration and will be discussed below.

Conclusions. Future research to establish acceptable, standardized, descriptive criteria is needed. The indicators identified above must be evaluated further, and the theoretical literature on the nature of mental disorders could be consulted in this endeavor. For example, to what extent would a dysfunction model of pathological grief apply (cf. Wakefield, 1992)? Or can Lilienfeld and Marino's (1995) notion of Roschian prototype(s), which would contain all the features of pathological grief(s), and marginal examples, be implemented here?

\section{Lack of Clarity in the Distinction/Overlap with Related Disorders}

That there is comorbidity of pathological grief with other syndromes, such as depression, anxiety disorders, or PTSD is generally accepted (for a review, see Kim \& Jacobs, 1991). The existence of comorbidity between pathological grief and other disorders, per se, could be recognized in the DSM system. The relationship between the phenomenon of grief and these other disorders is, however, complex, reflecting specific-to pathological grief-and more general-to diagnoses of mental disordersproblems in the establishment of comorbidity (cf. Caron \& Rutter, 1991). There are different ways that comorbidity has been identified in the literature with respect to pathological grief (cf. Horowitz et al., 1997; Parkes, 1996; Raphael et al., 1993). First, it has been argued that bereavement may precipitate onset of some related disorder 
(e.g., an anxiety disorder). Second, concurrent presence of a psychiatric disorder may precipitate pathological grief (e.g., the person may have been clinically depressed before bereavement occurred). Third, it is also conceivable that a bereaved person will suffer from a related disorder rather than pathological grief (e.g., after witnessing the violent death of a loved one, PTSD symptomatology may be the sole disorder). Fourth, the symptoms of disturbance of a specific individual may fit into different categories (e.g., PTSD as well as pathological grief). As such, comorbidity would be created by a conceptual overlap in disorders.

Conclusions. Different implications with respect to how pathological grief should be incorporated within a diagnostic category system emerge from the various approaches to diagnostic classification described above. Further examination and reconciliation between these positions will be necessary. Guidelines on how to go about this can be derived from the general literature on psychiatric classification and diagnosis (for more detailed discussions of diagnostic overlap, see, e.g., Caron \& Rutter, 1991; Maser \& Cloninger, 1990).

\section{GENERAL IMPLICATIONS}

Problems in defining the concept of pathological grief, and in trying to derive criteria to distinguish it from normal grief, have been identified and discussed above. It cannot be concluded that there are clear, consensual, operational criteria emerging from the definitions for use in a diagnostic system. There are no clear guidelines available to establish at what intensity and/or duration and/or type of symptomatology grief can be considered pathological. Nor is it evident precisely where and how pathological grief should be placed in a diagnostic system (among anxiety/depression/adjustment/stress-related disorders; as a new category or integrated in revision of currently existing ones?). What emerges is the need for greater accuracy in describing grief as pathology, further establishment of the validity (empirically) of the syndromes that have been associated with pathology, and finer delineation of the overlap and distinction between complicated grief and specific psychiatric disorders, such as depression and anxiety disorders.

Pathological grief is, by definition, a mental disorder, since pathology describes abnormal or diseased conditions in organisms. If it exists, it should, in principle, be included in a comprehensive classification system. The literature is quite consistent in claiming that pathological grief does exist. Some argue the need for pathological grief to be included in diagnostic systems anyway (after all, similar criticisms can be applied to other categories), because this would help to ensure that bereaved people in need are provided with easier access to health care and financial aid programs of various types and given the assistance that they need, and/or because it would further the recognition of pathological grief as a problem worthy and needy of professional attention. It could possibly also act as a stimulus to further empirical research on the phenomena of pathological grief, much as has happened in the case of PTSD. On the other hand, there is the danger, if change in diagnostic status takes place without due consideration of the shortcomings discussed above, that the need for further revision will not be sufficiently acknowledged, due to the fact that the category will have acquired status in an authoritative source.

The decision whether or not to include pathological grief within the formal diag- 
nostic nomenclature should not be taken on the basis of potential consequences, but according to the validity of the concept, as has been discussed in this article. Nevertheless, there should also be awareness of potential negative as well as positive ramifications of including such a category, at a time when researchers and clinicians are making a strong case for inclusion. Several concerns need further debate and expert evaluation. First, would incorporation of pathological grief into formal health-care systems bring about change in conceptualizations of grief? Would there be a tendency to pathologize even normal grief, to discount the function and value of grief as a normal emotional process? Again, comparisons with what has happened following the creation of the category PTSD gives cause for serious concern, particularly since the frequent use of the concept of PTSD has overclouded other trauma-related disturbances and cross-cultural variation in posttrauma responses (see Kleber \& Brom, 1992; Kleber et al., 1995). Second, the financial benefits associated with the formal introduction of a disorder category for both the bereaved themselves and for their clinicians are evident: third-party payment for treatment would become available (at least in some societies). The benefits versus costs to society are, however, less clear. What, for example, are the costs of intervention for a greater number of bereaved people, compared with the gains from decreasing the number of exacerbated problems (i.e., provision of intervention may prevent escalation of trouble)? Third, what would be the impact on other psychosocial systems (cf. Averill \& Nunley, 1993)? How, for example, would inclusion affect feelings of the bereaved themselves about personal efficacy, responsibility and control? What would the effect be on the informal support network if professional help were to become more readily available?

Important headway has been made by contemporary researchers and clinicians toward deciding whether and/or in what way pathological grief should be integrated within diagnostic systems. The issues raised in this article are, in our view, important to address in the continuation of this endeavor.

Acknowledgment-The authors wish to thank Scott Lilienfeld for his insightful comments on an earlier version of this article.

\section{REFERENCES}

Alarcon, R. D. (1984). Personality disorder as a pathogenic factor in bereavement. Journal of Nervous and Mental Disease, 172, 45-47.

American Psychiatric Association. (1987). Diagnostic and statistical manual of mental disorders (3rd ed., rev.). Washington, DC: Author.

American Psychiatric Association. (1994). Diagnostic and statistical manual of mental disorders (4th ed.). Washington, DC: Author.

Averill, J., \& Nunley, E. P. (1993). Grief as an emotion and as a disease: A social constructionist perspective. In M. Stroebe, W. Stroebe, \& R. O. Hansson (Eds.), Handbook of bereavement: Theory, research, and intervention (pp. 77-90). New York: Cambridge University Press.

Barlow, D. H. (1991). Special issue on diagnoses, dimensions, and DSM-IV: The Science of classification. Journal of Abnormal Psychology, 100, 243-412.

Bonanno, G. A., Keltner, D., Holen, A., \& Horowitz, M. J. (1995). When avoiding unpleasant emotions may not be such a bad thing: Verbal-autonomic response dissociation and midlife conjugal bereavement. Journal of Personality and Social Psychology, 69, 975-989.

Bowlby, J. (1963). Pathological mourning and childhood mourning. Journal of the American Psychoanalytic Association, 11, 500-541.

Bowlby, J. (1980). Attachment and loss. Vol. 3. Loss: Sadness and depression. London: Hogarth/New York: Basic Books. Brom, D., Kleber, R., \& van den Bout, J. (1993). Loss and trauma: Unity and diversity. In R. Malkinson, S. S. 
Rubin, \& E. Witztum (Eds.), Loss and bereavement in Jewish Society in Israel (pp. 39-50). Jerusalem: Cana Publishing House.

Brown, J. T., \& Stoudemire, G. A. (1983). Normal and pathological grief. Journal of the American Medical Association, 250, 378-382.

Caron, C., \& Rutter, M. (1991). Comorbidity in child psychopathology: Concepts, issues and research strategies. Journal of Child Psychology and Psychiatry, 32, 1063-1080.

Clayton, P. J. (1990). Bereavement and depression. Journal of Clinical Psychiatry, 51, 34-40.

Clayton, P. J., Halikas, J. A., \& Maurice, W. L. (1972). The depression of widowhood. British Journal of Psychiatry, 120, 71-76.

Deutsch, H. (1937). Absence of grief. Psychoanalytic Quarterly, 6, 12-22.

Follette, W. C. (1996). Development of theoretically coherent alternatives to the DSM-IV. Journal of Consulting and Clinical Psychology, 64, 1117-1202.

Garb, H. N. (1996). Taxometrics and the revision of diagnostic criteria. American Psychologist, 51, 553-554.

Hartz, G. (1986). Adult grief and its interface with mood disorder: Proposal for a new diagnosis of complicated bereavement. Comprehensive Psychiatry, 27, 60-64.

Horowitz, M. (1986). Stress response syndromes. Northvale, NJ: Aronson.

Horowitz, M., Bonanno, G., \& Holen, A. (1993). Pathological grief: Diagnosis and explanation. Psychosomatic Medicine, 55, 260-273.

Horowitz, M., Siegel, B., Holen, A., Bonanno, G., Milbrath, C., \& Stinson, C. (1997). Diagnostic criteria for complicated grief disorder. American Journal of Psychiatry, 154, 904-910.

Horowitz, M., Wilner, N., Marmar, C., \& Krupnick, J. (1980). Pathological grief and the activation of latent self images. American Journal of Psychiatry, 137, 1157-1160.

Jacobs, S. (1993). Pathologic grief: Maladaptation to loss. Washington, DC: American Psychiatric Press.

Jacobs, S., \& Douglas, L. (1979). Grief: A mediating process between a loss and illness. Comprehensive Psychiatry, 20, 165-175.

Jacobs, S., \& Kim, K. (1990). Psychiatric complications of bereavement. Psychiatric Annals, 20, 314-317.

Jacobs, S., Nelson, J., \& Zisook, S. (1987). Treating depressions of bereavement with antidepressants: A pilot study. Psychiatric Clinics of North America, 10, 501-510.

Karam, E. G. (1994). The nosological status of bereavement-related depressions. British Journal of Psychiatry, $165,48-52$.

Kendell, R. E. (1991). Relationship between the DSM-IV and the ICD-10. Journal of Abnormal Psychology, 100, 297-301.

Kim, K., \& Jacobs, S. (1991). Pathological grief and its relationship to other psychiatric disorders. Journal of Affective Disorders, 21, 257-263.

Kleber, R., \& Brom, D. (1992). Coping with trauma: Theory, prevention and treatment. Amsterdam: Swets \& Zeitlinger.

Kleber, R., Figley, C. R., \& Gersons, B. P. (Eds). (1995). Beyond trauma: Cultural and societal dynamics. New York: Plenum Press.

Lazarus, R. S., \& Folkman, S. (1984). Stress, appraisal, and coping. New York: Springer Publishing.

Lieberman, P. B., \& Jacobs, S. (1987). Bereavement and its complications in medical patients: A guide for consultation liaison psychiatrists. International Journal of Psychiatry in Medicine, 17, 23-29.

Lilienfeld, S. O., \& Marino, L. (1995). Mental disorder as a Roschian concept: A critique of Wakefield's "Harmful Dysfunction" analysis. Journal of Abnormal Psychology, 104, 411-420.

Lindemann, E. (1944). Symptomatology and management of acute grief. American Journal of Psychiatry, 101, 141-148.

Maser, J. D., \& Cloninger, C. R. (Eds.). (1990). Comorbidity of mood and anxiety disorders. Washington, DC: American Psychiatric Press.

McFarlane, A. C. (1995). The severity of the trauma: Issues about its role in Posttraumatic Stress Disorder. In: R. J. Kleber, C. R. Figley, \& B. P. Gersons (Eds.), Beyond trauma: Cultural and societal dynamics (pp. 3154). New York: Plenum Press.

Meehl, P. E. (1995). Bootstraps taxometrics: Solving the classification problem in psychopathology. American Psychologist, 50, 266-275.

Mezzich, J. E., Kleinman, A., Fabrega, H., \& Parron, D. L. (1996). Culture and psychiatric diagnosis: A DSM-IV perspective. Washington, DC: American Psychiatric Press.

Middleton, W., Burnett, P., Raphael, B., \& Martinek, N. (1996). The bereavement response: A cluster analysis. British Journal of Psychiatry, 169, 167-171.

Middleton, W., Raphael, B., Martinek, N., \& Misso, V. (1993). Pathological grief reactions. In M. Stroebe, W. Stroebe, \& R. O. Hansson (Eds.), Handbook of bereavement: Theory, research and intervention (pp. 44-61). New York: Cambridge University Press. 
Parkes, C. M. (1986). Bereavement: Studies of grief in adult life (2nd ed.). Harmondsworth, UK: Penguin/New York: International Universities Press.

Parkes, C. M. (1996). Bereavement: Studies of grief in adult life (3rd ed.). Harmondsworth, UK: Penguin/New York: International Universities Press.

Parkes, C. M., \& Weiss, R. (1983). Recovery from bereavement. New York: Basic Books.

Pasnau, R. O., Fawney, F. I., \& Fawney, N. (1987). Role of the physician in bereavement. Psychiatric Clinics of North America, 10, 109-120.

Pasternak, R. E., Reynolds, C. F., Schlernitzauer, M., Hoch, C. C., Buysse, D. J., Houck, P. R., \& Perel, J. M. (1991). Acute open-trial nortriptyline therapy of bereavement-related depression in late life. Journal of Clinical Psychiatry, 52, 307-310.

Prigerson, H., Bierhals, A., Kasl, S., Reynolds, C., Shear, M., Newsom, J., \& Jacobs, S. (1996). Complicated grief as a disorder distinct from bereavement-related depression and anxiety: A replication study. American Journal of Psychiatry, 153, 1484-1486.

Prigerson, H., Frank, E., Kasl, S., Reynolds, C., Anderson, M., Zubenko, G., Houck, P., George, C., \& Kupfer, D. (1995). Complicated grief and bereavement-related depression as distinct disorders: Preliminary empirical validation in elderly bereaved spouses. American Journal of Psychiatry, 152, 22-30.

Prigerson, H., Maciejewski, P., Reynolds, C., Bierhals, A., Newsom, J., Fasiczka, A., Frank, E., Doman, J., \& Miller, M. (1995). Inventory of complicated grief: A scale to measure maladaptive symptoms of loss. Psychiatry Research, 59, 65-79.

Prigerson, H., Shear, K., Newsom, J., Frank, E., Reynolds, C., Maciejewski, P., Houck, P., Bierhals, A., \& Kupfer, D. (1996). Anxiety among widowed elders: Is it distinct from depression and grief? Anxiety, 2, 1-12.

Rando, T. (1993). Treatment of complicated mourning. Champaign, IL: Research Press.

Raphael, B. (1989). Diagnostic criteria for bereavement reactions. Paper presented at the International Symposium on Pathologic Bereavement. Seattle, WA, May.

Raphael, B., Middleton, W., Martinek, N., \& Misso, V. (1993). Counseling and therapy of the bereaved. In M. Stroebe, W. Stroebe, \& R. O. Hansson (Eds.), Handbook of bereavement: Theory, research, and intervention (pp. 427-453). New York: Cambridge University Press.

Reeves, N. C., \& Boersma, F. J. (1990). The therapeutic use of ritual in maladaptive grieving. Omega, 20, 281-291.

Rynearson, E. K. (1987). Psychotherapy of pathologic grief: Revisions and limitations. Psychiatric Clinics of North America, 10, 487-500.

Sanders, C. (1989). Grief: The mourning after dealing with adult bereavement. New York: John Wiley \& Sons.

Sanders, C. M., Mauger, P. A., \& Strong, P. A. (1985/1991). A manual for the Grief Experience Inventory. Palo Alto, CA: Consulting Psychologists Press/Charlotte, NC: Center for the Study of Separation and Loss.

Schut, H., de Keijser, J., van den Bout, J., \& Dijkhuis, J. (1991). Post-traumatic stress symptoms in the first years of conjugal bereavement. Anxiety Research, 4, 225-234.

Shuchter, S. R., \& Zisook, S. (1993). The course of normal grief. In M. Stroebe, W. Stroebe, \& R. O. Hansson (Eds.), Handbook of bereavement: Theory, research and intervention (pp. 23-43). New York: Cambridge University Press.

Sireling, L., Cohen, D., \& Marks, I. (1988). Guided mourning for morbid grief: A replication. Behavior Therapy, 29, 121-132.

Stroebe, M. (1992). Coping with bereavement: A review of the grief work hypothesis. Omega: Journal of Death and Dying, 26, 19-42.

Stroebe, M., Schut, H., \& Stroebe, W. (1998). Trauma and grief: A comparative analysis. In J. Harvey (Ed.), Perspectives on loss: A sourcebook (pp. 81-96). Washington, DC: Taylor \& Francis.

Stroebe, W., \& Stroebe M. (1987). Bereavement and health. New York: Cambridge University Press.

Stroebe, M., \& Stroebe, W. (1991). Does "grief work" work? Journal of Consulting and Clinical Psychology, 59 , 479-482.

Wahl, C. W. (1970).The differential diagnosis of normal and neurotic grief following bereavement. Archives of the Foundation of Thanatology, 1, 137-141.

Wakefield, J. C. (1992). Disorder as harmful dysfunction: A conceptual critique of DSM-III-R's definition of mental disorder. Psychological Review, 99, 232-247.

Wambach, J. (1986). The grief process as a social construct. Omega, 16, 201-211.

Worden, W. (1991). Grief counseling and grief therapy: A handbook for the mental health practitioner. New York: Springer.

World Health Organization. (1992). ICD-10 classification of mental and behavioral disorders: Clinical description and diagnostic guidelines. Geneva: World Health Organization.

Wortman, C., \& Silver, R. (1989). The myths of coping with loss. Journal of Consulting and Clinical Psychology, 57, 349-357. 
Zisook, S., \& DeVaul, R. A. (1985). Unresolved grief. American Journal of Psychoanalysis, 45, 370-379.

Zisook, S., DeVaul, R. A., Click, M. A. (1982). Measuring symptoms of grief and bereavement. American Journal of Psychiatry, 139, 1590-1593.

Zisook, S., \& Lyons, L. (1990). Bereavement and unresolved grief in psychiatric outpatients. Omega, 20, 307-322. 